\title{
FONTES FRANCISCANAS: HISTORIOGRAFIA FRANCISCANA BRASILEIRA
}

\author{
Tania Conceição Iglesias ${ }^{1}$
}

\begin{abstract}
RESUMO
artigo de divulgação de fontes documentais e bibliográficas que abordam a ação missionária referentes à Ordem franciscana no Brasil Colonial (1500-1822) decorrente de investigações desenvolvidas entre 2005 a $2010^{2}$. Este texto é o segundo da série de um projeto de três publicações sobre o assunto. No primeiro artigo foram apresentadas as obras Clássicas da Ordem franciscana, priorizando as Crônicas. O presente oferece as fontes bibliográficas da historiografia franciscana no Brasil Colonial, bem como, uma análise dos temas por ela abordados.

Palavras-chave: Fontes Documentais, Brasil, Educação Colonial, franciscanos, Historiografia.
\end{abstract}

\section{FRANCISCAN SOURCES: FRANCISCAN BRAZILIAN HISTORIOGRAPHY}

\begin{abstract}
This article talks about the divulgation of bibliographical and documentary sources that refer to the missionary action of the franciscan Order in Colonial Brazil (1500 - 1822), resulting from the investigations which were developed between 2005 to 2010 . This text is the second of a series of the three publications about the franciscan sources. In the first article we presented the Classical works of the franciscan Order, prioritizing their Chronicles. This one offers the bibliographical sources of the franciscan historiography in colonial Brazil as well as an analysis of containable issues inside of this historiography.

Keywords: Documentary Sources, Brazil, Colonial Education, Franciscan Historiography.
\end{abstract}

Este texto, baseado nos estudo e pesquisas desenvolvidas no processo de elaboração da tese doutoral intitulada: A Experiência Educativa da Ordem Franciscana: aplicação na América e sua influência no Brasil Colonial ${ }^{3}$ é o segundo da série de artigos de divulgação das fontes documentais e bibliográficas sobre a ação missionária dos franciscanos nos Período Colonial brasileiro que tem como propósito a divulgação dessas produções e documentos nos meios acadêmicos, contribuindo, dessa forma, para o conhecimento do assunto e para o acréscimo deste estudo à tênue produção existente a respeito tema. No primeiro artigo foram apresentadas as obras Clássicas da Ordem, priorizando as Crônicas mais antigas, que por seu valor histórico, são consideradas fontes documentais. Agora, serão apresentadas as fontes bibliográficas - produções específicas da ação missionária na historiografia franciscana brasileira - com o objetivo de divulgá-las e oferecer uma análise dos conteúdos abordados. O trabalho, que tem como base pesquisas realizada no Brasil, respeitará a ordem cronológica em que essas fontes bibliográficas foram produzidas.

$\mathrm{Na}$ literatura sobre a história dos franciscanos no Brasil, verifica-se que foram muitos os conflitos estabelecidos entre ordens religiosas durante os primeiros séculos de atividades missionárias ${ }^{4}$, de maneira especial entre os jesuítas e franciscanos. Esses conflitos não raramente resultaram na expulsão de uma ou de outra Ordem das Missões em que se estabeleceram. A animosidade entre as duas Ordens é histórica e se apresentou em todos os espaços onde se fizeram presentes simultaneamente, como na Índia, na China e no Japão ${ }^{5}$. 
No Brasil, elas se manifestaram desde o princípio da colonização, durante os trinta anos de atividades missionárias franciscanas na Paraíba (1589-1619) ${ }^{6}$, quando por decreto do Rei Felipe II, os jesuítas tiveram que abandonar as Missões do Braço do Peixe e entregá-las aos franciscanos. Em 1640, em São Paulo, em conflito com os colonos e a câmara, devido à defesa da causa indígena, os jesuítas foram intimados a se retirar da capitania para onde só voltaram em 1653, treze anos depois - fato que eles remetem à ajuda dos franciscanos que permaneceram missionando naquela região. Em 1640, no Rio de Janeiro, pelo mesmo motivo, o povo e a câmara se uniram contra os Jesuítas, e os padres foram expulsos por horas da cidade, mas puderam voltar mediante declaração de que só se envolveriam com a administração dos índios em suas aldeias. Em 1661, no Maranhão e Grão-Pará ${ }^{7}$, os jesuítas, inclusive o Padre Antonio Vieira, foram expulsos pela primeira vez para o reino, tendo voltado um ano depois. Finalmente, em 1684, foram expulsos pela segunda vez do Maranhão; todavia, o Regimento das Missões ${ }^{8}$ de 1686 restituiu aos jesuítas não só as antigas Missões da região, mas também seu governo espiritual, temporal e político.

Enquanto no plano civil, o que sustentou os conflitos entre os religiosos e os colonos fora a questão da escravidão indígena, entre as Ordens religiosas no Brasil, eles foram quase sempre motivados pelas disputas das regiões de missão, devido ao direito de monopólio defendido pelos jesuítas na catequização. Habitualmente, as autoridades locais adotavam o critério da precedência na região missionária para solucionar os problemas entre as Ordens em relação à distribuição das Missões. A anterioridade do trabalho catequético assegurava, dessa forma, as melhores regiões na disputa das Missões, razão pela qual a questão da primazia é imperante no trabalho dos historiadores franciscanos.

A historiografia franciscana mostra-se, nesse sentido, combatente frente às demais produções historiográficas, principalmente as dos historiadores jesuítas, que, segundo a literatura franciscana consultada, silenciaram sobre a questão dos conflitos e as contendas que tiveram resultados favoráveis à Ordem franciscana.

Ressentem-se a maioria dos autores franciscanos da negligência da historiografia, seja ela jesuítica, ou não, de fatos históricos importantes que tiveram como conseqüência a subestimação da ação missionária franciscana e de outras ordens religiosas. Também acusam os historiadores de terem construído uma História partidária, consensual e apologética, que concede aos jesuítas a hegemonia absoluta sobre a catequização no Brasil Colonial. Hegemonia essa, que segundo os autores estudados, fora construída com o concurso da escrita da história.

Sem entrar no mérito da questão, que já foi analisada de forma suficiente por outros pesquisadores $^{9}$, constata-se um longo período no qual não se encontra nenhuma publicação sobre a ação dos franciscanos no Período Colonial. A obra de Jaboatão que data de 1761 foi a que antecedeu a de 1924 que se passará agora a apresentar. Portanto, só depois de mais de um século é que elas reaparecem.

\section{HISTORIOGRAFIA FRANCISCANA BRASILEIRA}

O ano de 1924 marca o reinício da publicação de obras sobre a história dos franciscanos no Brasil. Frei Samuel Tetteroo (1875-1934) ${ }^{10}$, em comemoração ao sétimo centenário da impressão das cinco chagas de Jesus Cristo ao Corpo de São Francisco, ${ }^{11}$ publica "A Ordem dos Frades Menores no Brasil: Resumo Histórico-Chronológico 15001924”. Como sugere seu título, o livro trata de um relato da presença franciscana no Brasil 
desde sua descoberta até 1924 e utiliza como fontes, além das crônicas da Ordem, dentre as quais as de Jaboatão são as mais citadas, apontamentos, registros e anotações elaborados por confrades. Interessante observar dessa obra é que o tema que moveu os primeiros cronistas franciscanos, qual seja, a primazia Seráfica no Brasil, volta a inspirar os autores franciscanos dessa época. Já no prólogo do livro, fica explícita a questão. Frei Samuel Tetteroo diz tratar-se de um quadro histórico das Ordens e Congregações religiosas no Brasil e afirma:

De algum modo as definir um pouco mais, por quanto respeita a Ordem dos Frades Menores, na precedência histórica a mais antiga do Brazil, a que veio ao Brazil primeiro que as demais religiões... que aqui trouxe o zelo da salvação das almas e, neste abençoado torrão se instalaram. [sic]

O Livro, não obstante careça de sistematização metodológica, como nota explicativa oferece o relato do início da presença franciscana e do desenvolvimento das Custódias, Províncias, dos Comissariados e das Missões da Ordem no Brasil. Mas, não se limita aos dados oferecidos por bibliografias anteriores, pois o autor, ainda que de forma resumida, avança até o ano de 1924 com notícias históricas da Ordem. No último capítulo, para demonstrar e defender a primazia seráfica na obra missionária, o autor se refere às Missões franciscanas na Terra Santa, empreendidas, entre outros, pelo próprio patriarca da Ordem São Francisco de Assis, em $1219^{12}$.

Em 1937, foi publicada uma interessante obra sobre os franciscanos no Brasil. Trata-se do trabalho de Frei Fidelis M. de Primerio (1885-1968) ${ }^{13}$, escrita em 1936, intitulada "Capuchinhos em Terras de Santa Cruz nos Séculos XVII, XVIII e XIX". O livro apresenta a história dos capuchinhos no Brasil e abrange um longo período que se iniciou na Colônia em 1612, com a chegada dos missionários franceses ao Maranhão e se estendeu até o Império. Nela, o autor relata a presença e atuação dos frades capuchinhos, que eram de origem francesa e inglesa, na atividade missionária e catequética no Brasil.

A obra desperta a atenção por vários motivos: por inaugurar os estudos que se dedicam à história de ramos específicos da Ordem franciscana; por trazer à tona a questão de se apresentarem missionando em terras brasileiras, frades não ligados diretamente ao Padroado $^{14}$ Régio Português ou Espanhol, mas filiados à Propaganda Fidei ${ }^{15}$ sob o comando direto de Roma, fato que remete a uma importante questão a respeito da retomada e centralização do poder sobre as Ordens missionárias pela Sé romana; por demonstrar, por meio de documentos, como se deu a dissipação dos arquivos documentais dos capuchinhos no Brasil; e, principalmente, por conseguir captar e relatar, em linguagem simples, os conflitos que se estabeleceram entre Roma e os soberanos portugueses em relação ao direito de Padroado, incluindo as desavenças entre os franciscanos portugueses e os capuchinhos que missionavam simultaneamente no período, que inúmeras vezes originaram problemas no seio da Ordem.

O livro, ao contrário da maioria dos trabalhos elaborados até então, afasta-se da questão da primazia, dedicando-se à produção com recorte delimitado da história dos franciscanos no Brasil. Sua principal contribuição foi captar o movimento que elucida muitos conflitos ocorridos entre os missionários brasileiros.

Voltando à questão da primazia e seguindo a mesma direção que frei Tetteroo, embora de modo mais sistematizado, apresenta-se frei Dagoberto Romag OFM (18991982) ${ }^{16}$, que publicou em 1940, a sua "Historia dos Franciscanos no Brasil".

Frei Romag escreveu sobre o mesmo objeto e com o mesmo objetivo que frei 
Tetteroo, mas oferece recorte temporal mais definido, notas explicativas e pesquisa mais aprofundada em fontes primárias. Avança a questão da historiografia franciscana quando aborda o problema da escassez de fontes e aponta para a necessidade de novas pesquisas sobre os franciscanos no Brasil, questão que, a partir de então, passa a ser constante nos escritos dos autores franciscanos.

O livro aborda como tema principal a história da primeira Custódia franciscana no Brasil, desde sua fundação em 1584 até a sua elevação à Província independente de Portugal em $1657^{17}$. Destaca a presença não apenas anterior, mas, única dos franciscanos durante os cinquienta primeiros anos de colonização ${ }^{18}$ e enfatiza a existência de outras Missões ${ }^{19}$ empreendidas por frades franciscanos no Brasil até 1659, independentes da Custódia portuguesa.

O trabalho de frei Romag, ainda que discorra sobre a história franciscana já arrolada por cronistas e autores anteriores, traz à tona duas questões importantes para a historiografia de modo geral. A primeira diz respeito a pouca alusão feita às Missões anteriores àquelas oficializadas por Portugal sob o comando do Padroado; e a segunda, a pouca atenção oferecida pela literatura brasileira à colonização do Brasil por parte de outros países. Esses são pontos-chave para a compreensão da questão das disputas sobre a primazia entre franciscanos e jesuítas no Período Colonial brasileiro. Mesmo não tento sido abordada diretamente por Frei Romag, a referência a tais disputas permanece latente em seu trabalho.

Frei Odulfo Van Der Vat (1900-1966) ${ }^{20}$, embora não possa ser classificado como um autor que escreveu sobre a História dos Franciscanos no Brasil, colaborou no sentido de minimizar a lacuna nos estudos franciscanos quando, em 1943, escreveu um artigo intitulado "Franciscanos Espanhóis na Costa do Brasil", publicado no volume 1 da Revista Vozes, de Petrópolis. Esse artigo, que discute da presença dos franciscanos espanhóis durante o domínio do reino espanhol sobre o reino de Portugal a partir de 1580, toma a correspondência das expedições espanholas durante o período da dominação como fonte para, em confronto com as notícias fornecidas pelos cronistas coloniais, discorrer sobre a vinda de vários franciscanos espanhóis que se estabeleceram no Brasil por ordem do Rei de Espanha, bem como as suas atividades em várias regiões do Brasil, destacando a primeira comunidade franciscana de São Paulo.

Respondendo aos clamores de Frei Romag, apresenta-se Basílio Röwer (18771958) ${ }^{21}$. Respeitado historiador da Ordem franciscana no Brasil, foi sócio honorário do Instituto Histórico do Rio de Janeiro, e consagrado como doutor honoris causa da Universidade São Boaventura, nos Estados Unidos. Frei Basílio Röwer, historiador e compositor, escreveu várias obras; e não obstante possua qualidades de compositor sacro ${ }^{22}$, o que se destaca é sua dedicação à historiografia franciscana brasileira. Toda a obra de Frei Röwer foi produzida no Brasil. Exerceu várias funções dentro da Ordem ${ }^{23}$, tendo deixado uma inestimável produção histórica.

Sua obra constitui trabalho historiográfico bem fundamentado. Embora tendo se lamentado da falta de fontes, ele não se conformou e pesquisou intensamente documentos originais, trazendo grande contribuição nesse sentido. Não escreveu uma história geral da Ordem, mas produziu trabalhos que retratam a história de várias instituições em particular, que, em seu conjunto, constituem as fontes mais sistematizadas para a pesquisa histórica. Ele não foi um compilador de documentos, pois também pesquisou e analisou temas que mesmo já tendo sido abordados por outros historiadores e cronistas, não apresentavam ainda exames mais detidos da questão. Dessa forma, não se prendeu à defesa da primazia dos franciscanos em relação a outras Ordens religiosas, que é particularidade da bibliografia anterior. 
Em “Ordem Franciscana no Brasil”, de 1942, por exemplo, Frei Basílio Röwer, no capítulo IV, dedica um item às atividades do ensino primário, secundário e superior praticado pelos freis franciscanos no Brasil. O autor escreve que, desde que os franciscanos se estabeleceram no Brasil, já se preocuparam em disseminar a instrução. Afirma que

[...] O fim principal, por certo, é a educação moral e religiosa, mas com suas escolas realizaram e realizam também uma obra eminentemente cívica e social. Apenas ocuparam o primeiro Convento em Olinda, fundaram um educandário para os filhos dos índios. Ensinavam-nos a ler, escrever e instruíam-nos no canto e na música. Arrebanharam em seguida os índios em muitas aldeias, nas capitanias de Pernambuco, Paraíba e no Pará-Maranhão, e por via de regra levantavam também uma escola junto à capela e residência dos missionários. (RÖWER, 1942, p. 99-100)

Nesse trecho, está implícita a discussão do autor. Sua preocupação já não é mais sobre a precedência, e sim sobre a contribuição da ação franciscana que, para ele, não se limitou à dilatação da fé, mas "contribuiu largamente para a formação da nossa nacionalidade" (RÖWER, 1942, p. 6)

A preocupação com a escassez de fontes, apresentada em todas as obras de Frei Röwer, não remete à sua inexistência, mas à sua falta de sistematização. É sobre a sistematização dos documentos a respeito da Ordem que o autor se debruça, pois, para ele, uma História dos franciscanos no Brasil ainda estava para ser escrita e só seria possível a partir da sistematização de fontes documentais dos vários segmentos da Ordem. Elaborou uma obra relevante nesse sentido, na medida em que conseguiu, nos trabalhos que realizou, propiciar um vasto e bem documentado material de pesquisa que, embora trate nomeadamente de certas Províncias e Conventos da Ordem, auxiliam sobremaneira os historiadores que se dedicam à pesquisa da história dos franciscanos no Brasil. Ele reforça, no entanto, que pesquisas subseqüentes deveriam ampliar e aprofundar o quadro de pesquisas traçado por ele.

Frei Jacinto de Palazzolo"24, entre outras obras, publicou, em 1966, a sua "Crônica dos Capuchinhos do Rio de Janeiro". Assim como frei Fidelis de Primerio, dedicou-se à história dos capuchinhos. Trabalho de recorte mais delimitado é o relato histórico dos capuchinhos no Rio de Janeiro desde sua chegada em 1650 até 1965, quando finalizou a obra. Outro importante trabalho de frei Jacinto, publicado pela primeira vez pela Editora Vozes, Petrópolis em 1945 e intitulado "Nas Selvas dos Vales do Mucuri e do Doce", apresenta a história das atividades missionárias dos frades capuchinhos entre os rios Mucuri e Doce em Minas Gerais. Traz relevantes informações e documentos que mostram a perspectiva capuchinha, que se debatia entre a experiência prática do sertão e os conhecimentos e as expectativas que traziam a respeito dos povos indígenas.

O livro não apresenta novas questões ao campo historiográfico franciscano, mas contribui, respondendo aos anseios dos historiadores no sentido de aprofundar as pesquisas sobre as atividades dos ramos específicos da Ordem franciscana no Brasil.

Dando prosseguimento ao trabalho de Röwer, segue Frei Venâncio Willeke. (19061978) ${ }^{25}$. O escritor não se dedicou a escrever uma história franciscana. Em seu trabalho, constam livros, prefácios, artigos em revistas, jornais, conferências e palestras pronunciadas em diversas cerimônias. Mas todas elas gravitam em torno de um tema em comum: franciscanos no Brasil. Também escreveu sobre os cronistas da Ordem e personalidades da época ${ }^{26}$. 
É vasta sua produção sobre os franciscanos no Brasil, destacando-se: "Resumo histórico do Convento de Santo Antonio e do santuário do Sr. Santo Cristo de Ipojuca", Ipojuca, 1938; "São Francisco das Chagas de Canindé", Salvador, 1962; "Antologia do Convento da Penha", Vitória, 1974; "Missões Franciscanas no Brasil 1500-1975", Petrópolis, 1974; "Franciscanos na História do Brasil", Petrópolis, 1977; "Franciscanos no Maranhão e Piauí 1600-1878”; 1952-1977, Petrópolis, 1978; “As Missões da Custódia de Santo Antonio do Brasil 1585-1619”, Recife, 1957. Além dessas obras, foram encontrados outros trabalhos do autor sobre o mesmo assunto e que foram publicados em revistas no Brasil e no exterior ${ }^{27}$.

Por ser grande estudioso da historiografia franciscana, Frei Willeke procurou em seu trabalho imprimir uma visão mais crítica a respeito dos fatos históricos sobre a Ordem, descritos pelos escritores anteriores. Para ele, os frades, sempre animados pelo fervor missionário, deixaram transparecer certa visão de defesa apaixonada, subjetiva e apologética sobre os acontecimentos históricos. Na introdução de "As Missões da Custódia de Santo Antonio do Brasil", de 1957, Willeke (1977, p. 247) demonstra a distinção que pretende imprimir à sua produção quando afirma: "A missionologia moderna procura libertar-se dessa falta de objetividade, substituindo, há um tempo, o estilo apologético dos historiadores, até pouco em voga, pela exposição crítica e realista".

Entretanto, é possível perceber que ele não foge muito à regra dos demais autores franciscanos. A questão de fundo que transparece na obra do autor é a mesma abordada por seus confrades anteriores, qual seja, a primazia seráfica no Brasil, porém ele imprime ao tema um tratamento mais objetivo e sistematizado. Confronta os dados oferecidos pelas crônicas com os documentos existentes e tenta situá-los em um contexto mais amplo que permita a compreensão dos processos históricos constitutivos. Mas não deixa de reforçar a tese da primazia, notadamente quando busca, por meio de seus escritos sobre os membros ilustres da Ordem, a sua valorização e importância para o melhor conhecimento da história do Brasil. Dessa forma, sua obra, não obstante apresente caráter mais científico em relação ao tratamento das fontes e seja um sério e bem documentado estudo histórico, não abandona a questão primordial que animou toda a historiografia franciscana no Brasil sobre a sua precedência em relação a outras ordens missionárias. Também não deixa, a exemplo de Röwer, de se preocupar em destacar a presença da Ordem franciscana no Brasil, anteriormente instituídas pela colonização portuguesa, como importante chave de leitura sobre a contribuição franciscana no Brasil.

Portanto, o trabalho de frei Willeke é fundamental para a pesquisa de temas específicos sobre a contribuição dos Franciscanos no Brasil, na medida em que fornece estudos mais aprofundados, delimitados e atualizados sobre as atividades desenvolvidas pelos frades no Brasil.

Outro importante livro que se encontra sobre os franciscanos no Brasil é o escrito por Maria do Carmo Tavares de Miranda $^{28}$, publicado pela Universidade Federal de Pernambuco em 1969, intitulado "Os Franciscanos e a Formação do Brasil". Filósofa, escritora e colaboradora de Gilberto Freyre, Miranda é autora de várias obras ${ }^{29}$. Não pode ser considerada uma estudiosa da história franciscana; entretanto, não poderia deixar de estar presente na revisão que ora se apresenta porque o trabalho que desenvolveu sobre eles constitui inestimável contribuição, devido ao tratamento analítico que ela imprime ao tema e pelo fato de ser amplamente citada pelos escritores atuais. Não se trata de retratar a história dos franciscanos, mas de analisá-la a partir de sua contribuição para a formação da personalidade do brasileiro, abordando questões do campo educacional para o qual a autora acredita ter sido relevante a ação franciscana no Brasil.

Sophia Albuquerque Lyra (1903-?) ${ }^{30}$, escritora e pesquisadora do franciscanismo ${ }^{31}$, 
também contribuiu para a produção sobre a história dos franciscanos no Brasil. A autora escreveu, em 1978, "São Francisco de Assis e o Brasil", publicado no Rio de Janeiro pela Editora José Olympio. Embora seja uma estudiosa da vida de São Francisco de Assis, tomou a tarefa de escrever sobre a Ordem franciscana no Brasil para colaborar e amenizar a falta de fontes documentais, que também para ela se constituía em um entrave para a compreensão da história franciscana no país. Seu trabalho se embasou na bibliografia franciscana brasileira e em vasta pesquisa documental que efetuou no Brasil e na Europa e se constitui, segundo a própria pesquisadora, apenas em um resumo do vasto material que levantou e que disponibilizou para trabalhos posteriores mais aprofundados. Trata-se da história dos franciscanos, já produzida em confronto com as fontes obtidas, em que a autora corrige e amplia as informações contidas nas obras de seus predecessores. Compreende um grande período histórico que se inicia com Frei Henrique de Coimbra, estendendo-se até o período republicano. Possui caráter eminentemente de defesa da precedência e relevância do trabalho missionário dos franciscanos no Brasil.

Frei Hugo Fragoso ${ }^{32}$, estudioso da Ordem, é um grande colaborador da historiografia franciscana atualmente. Ele acredita que não existe uma história sobre a grande família franciscana no Brasil. Segundo o autor, o que existe são fragmentos dessas histórias, que, em sua maioria, tratam de memórias. Essas, embora relevantes não trazem uma visão de conjunto necessária à compreensão mais aprofundada do significado do trabalho missionário desenvolvido pelos franciscanos no Brasil.

Colaborando com a tarefa, frei Hugo tem desenvolvido alguns trabalhos ${ }^{33}$, entre os quais se destaca o que foi publicado no livro "Entre Memória e Utopia", publicado pela Editora Vozes, Petrópolis em 1994. No referido trabalho, que se intitula "A presença Franciscana no Brasil em Cinco Séculos de Evangelização", o autor inicia a busca por tal visão de conjunto, mas já reconhecendo que se trata de tarefa árdua. Embora venha sendo tentado pelo Departamento de História Franciscana, o empreendimento ainda não conseguiu passar do primeiro passo, qual seja, o levantamento bibliográfico sobre tal presença histórica.

O trabalho de frei Hugo apresenta duas questões importantes que se quer ressaltar. A primeira diz respeito ao embasamento mais crítico da visão de história que ele imprime ao trabalho, e a segunda, à exposição de outro tema fundamental para a análise da história dos franciscanos: a atuação da mulher franciscana no incremento da Ordem, notadamente no campo educacional, que, mesmo tendo sido sublinhado por outros autores, é carente de estudos na história da Ordem no Brasil ${ }^{34}$.

Frei Hugo Fragoso concebe a história como um processo do qual a memória é apenas uma dimensão. Conforme afirma,

A Memória de uma caminhada é apenas uma dimensão da história, mas esta envolve uma abrangência muito maior que a dimensão "memorial". Pois a história é um processo vital, a abarcar toda a vida no seu dinamismo evolutivo. [...] Nesse processo em que se desenvolve a história, há linhas direcionais que lhe imprimem um rumo determinado. $(1994$, p.33)

É essa concepção de história que ele tenta aplicar à análise da história dos franciscanos, enfocando-a a partir da vinculação ao poder então estabelecido em relação à obra evangelizadora no Período Colonial. Considera a historiografia franciscana uma elaboração que traz em si a ótica dos sujeitos inseridos em um tempo e em um espaço determinados e que, por conseguinte, apresentam o ponto de vista daqueles que a 
produziram. Dessa forma, propõe não somente a produção da história franciscana por meio de uma visão de conjunto, mas também a sua releitura, considerando outros determinantes, como o importante papel da mulher franciscana no processo evangelizador no Brasil.

Importante ressaltar que a educação feminina é um tema expressivo e constante na Ordem franciscana não só pelo trabalho educativo desenvolvido pelas religiosas, mas também pela preocupação com a educação da mulher, que, mesmo tendo se realizado remotamente na História da América por franciscanos, acabou não se efetivando no Brasil Colonial. Desde o início da evangelização americana, os frades franciscanos já se preocuparam em criar escolas femininas.

Existem bons trabalhos publicados a respeito das ordens religiosas femininas no Brasil, dentre os quais o livro de Leila Mezan Algranti: "Honradas e Devotas: Mulheres da Colônia", editado pela Editora José Olympio em 1993. Em tal livro, a autora analisa a condição feminina nos Conventos e recolhimentos do sudeste do Brasil nos anos de 1750 a 1822. Outros trabalhos merecedores de destaque são: "Educação da Mulher no Brasil Colônia", de Arilda Ribeiro Miranda, publicado em Campinas em 1987, em que a autora discute a educação oferecida às mulheres no Brasil Colonial; "A Vida Religiosa no Brasil: enfoques históricos", de Riolando Azzi, editado pela Editora Paulinas em 1983, no qual o autor discute a vida religiosa feminina no Brasil Colonial; e "Os religiosos no Brasil: enfoques históricos", também editado pela Paulinas em 1986, organizado por Riolando Azzi e José Oscar Beozzo, e que apresenta vários artigos sobre congregações religiosas femininas, havendo notadamente um artigo que discute a prática político-religiosa das congregações femininas no Brasil.

Conscientes da necessidade de estudos mais aprofundados e da elaboração sistematizada de sua história, os franciscanos têm despendido esforços no sentido de promover, por meio de incentivo à pesquisa, a produção escrita da história da Ordem. $\mathrm{O}$ trabalho vem sendo desenvolvido pelo Centro Franciscano do Brasil - $\mathrm{CFB}^{35}$ - sede da Família Franciscana do Brasil - $\mathrm{FFB}^{36}$ - localizado em Petrópolis, que abriga vários serviços da instituição, entre eles o DEHIF $^{37}$ - Departamento de Estudos de História Franciscana, que atualmente é dirigido pelo Frei Sandro Roberto da Costa (1962-) ${ }^{38}$, que anima e coordena as atividades do departamento. Frei Sandro da Costa, assim como Frei Hugo Fragoso, também acredita que ainda não foi produzida uma história dos franciscanos no Brasil. Ambos asseveram que, para a consecução de tal tarefa, faz-se necessário desenvolver pesquisas mais sistematizadas sob o ponto de vista metodológico, histórico e crítico sobre as várias atividades da Ordem, na intenção não só da perscrutação de fontes históricas, mas também e, sobretudo da produção de análises que considerem os determinantes sociais, políticos e culturais de tais ações. Nesse sentido, o DEHIF tem organizado encontros e cursos anuais sobre historiografia franciscana nos quais pretende formar os historiadores franciscanos para a tarefa.

Além de historiadores da Ordem, o DEHIF também tem incentivado e apoiado iniciativas de pesquisadores que se dedicam ao tema. Os trabalhos produzidos estão sendo publicados pelo Conselho Editorial Franciscano (CONEF), Serviço do Centro Franciscano de publicações de livros e outros subsídios que visam a um maior conhecimento e aprofundamento do Carisma Franciscano. Nesse sentido, merecem destaque os livros "Brasil Franciscano", organizado por frei Alfredo Sganzerla de 1998 e "Perfil Franciscano ano 2000: 500 anos de presença no Brasil", editado em 2000, organizado por Frei Silvestre Gialdi. Ambos tratam da coletânea de estudos históricos sobre a Ordem franciscana. Outros artigos sobre o mesmo tema estão sendo veiculados, principalmente pela Revista Franciscana, editada semestralmente desde 2001 pela FFB.

Em todas as obras aqui apresentadas, existem claras diferenças em relação à 
metodologia utilizada pelos autores; mas, ao mesmo tempo, é possível perceber a aproximação temática que os une.

No que concerne aos primeiros trabalhos produzidos, tratam-se, indiscutivelmente, de relatos de caráter apologético sem preocupação com questões metodológicas. São narrativas de linguagem simples sobre as atividades missionárias no Brasil. A partir da Crônica de frei Jaboatão, percebe-se a preocupação em relação tanto à metodologia quanto a uma questão temática. O autor, tomando a defesa explícita da Ordem, utiliza-se de documentos e de bibliografias existentes para afirmar a primazia franciscana na obra missionária no Brasil. Os autores que o sucedem procuram aprofundar a questão do método, mas o eixo central em torno do qual giram, diz respeito também à questão da precedência no trabalho missionário dos franciscanos.

As obras posteriores questionam a lacuna historiográfica sobre os franciscanos no Brasil e trazem à discussão a escassez das fontes documentais, para as quais procuram responder por meio de levantamentos de fontes de pesquisa e constituem-se em compilações documentais sobre as atividades da Ordem.

É com frei Basílio Röwer que se pode identificar uma nova fase na historiografia franciscana no Brasil. A partir de seu trabalho, percebe-se uma maior preocupação com a sistematização e o tratamento das fontes disponíveis, que, para ele, não constituíam entrave para a produção da história dos franciscanos. Apesar de não ter escrito uma história dos franciscanos, ele trouxe à discussão novos temas que deveriam ser explorados para possibilitar uma maior compreensão das atividades dos franciscanos e permitirem o dimensionamento dessa ação e, assim, a possibilidade da produção de uma história dos franciscanos no Brasil.

A partir de então, verifica-se uma crescente preocupação dos autores em relação ao tratamento metodológico aplicado às produções históricas da Ordem, no sentido de aplicarlhe caráter mais aprofundado e sistematizado. Entretanto, não há dúvida quanto à questão central que perpassa toda a produção aqui apresentada. Todas elas são animadas pela defesa da experiência anterior e única dos franciscanos na obra missionária nos primeiros tempos coloniais bem como sua permanência no decorrer do desenvolvimento histórico no País.

Devido à variedade de aspectos, períodos e espaços que abordam, não possam ser classificados como "História dos franciscanos no Brasil", em seu conjunto, esses trabalhos apresentam um rico material de pesquisa, porque são importantes fontes documentais ainda pouco exploradas que retratam questões interessantes ao debate e produções acadêmicas, notadamente para a análise e compreensão do desenvolvimento do campo educacional brasileiro.

O debate suscitado em torno da insistente defesa da primazia seráfica no Brasil presente na literatura franciscana é um elemento que exige a busca de compreensão do processo que a gerou e na qual foi produzida. É preciso, pois, considerá-las, não para dar continuidade à questão nuclear que sustentou até agora, mas, e muito especialmente, para avançar o conhecimento que se tem sobre a constituição do país, que ainda sabe muito pouco da base de sua formação. Não obstante, é preciso divulgar entre a comunidade acadêmica as inúmeras possibilidades que essas fontes documentais oferecem para o aprofundamento dos conhecimentos sobre o Período Colonial brasileiro, por essa razão, a esse, seguira o terceiro artigo da série de divulgação das fontes documentais bibliográficas que se desenvolve no momento. Nesse sentido, o próximo artigo se intitulará, Fontes Franciscanas: Os Franciscanos na historiografia do Brasil e na História da Educação Brasileira. 


\section{BIBLIOGRAFIA}

ALGRANTI, Leila Mezan. Honradas e Devotas: mulheres da colonia. Rio de Janeiro: José Olympio Brasília: Edunb, 1993.

ARNS, Alice Bertoli. Laguna: uma esquecida epopéia de franciscanos e bandeirantes, Paranaguá, 1975.

AZZI, Riolando. A Evangelização e a catequese na história religiosa do Brasil. Pesquisa 1.14 do P.P.C... História religiosa do Brasil, 7. 1969, dat.

BEOZZO, José Oscar (orgs). Os religiosos no Brasil: enfoques históricos. São Paulo, Paulinas, 1986.

A Vida religiosa feminina no Brasil: síntese histórica. Pesquisa 1.14. Do P.P.C. História religiosa do Brasil, 2. 1969, dat.

As Ordens religiosas masculinas na história da Igreja do Brasil: síntese histórica. Pesquisa 1.14 do P.P.C. História religiosa do Brasil, 4. 1969, dat.

O Episcopado na história da Igreja do Brasil: síntese histórica. Pesquisa 1.14 do P.P.C. História religiosa do Brasil, 5. 1969, dat.

Os Seminários e as vocações sacerdotais no Brasil. Pesquisa 1.14 do P.P.C. História religiosa do Brasil, 1. 1968, dat.

COSTA, Sandro Roberto da. Processo de Decadência da Província Franciscana da Imaculada Conceição do Brasil e Tentativas de Reforma - 1810-1855. Pontifícia Universidade Gregoriana, Roma 2000.

FRAGOSO, Hugo. Presença Franciscana no Brasil em Cinco Séculos de Evangelização: Entre Memória e Utopia, Vozes: Petrópolis, 1994.

LYRA, Sophia A. São Francisco de Assis e o Brasil. Rio de Janeiro: José Olympio, 1978.

MIRANDA, Maria do Carmo Tavares de. Os Franciscanos e a Formação do Brasil. Recife: Universidade Federal de Pernambuco, 1969.

PALAZZOLO, Jacinto de. Crônica dos Capuchinhos do Rio De Janeiro. Guanabara 1965, Ano do Iv Centenário da Fundação da Cidade de São Sebastião Rio De Janeiro. Petrópolis: Vozes, 1966.

PRIMERIO, Fidelis M. de Os Missionários Capuchinhos no Brasil. São Paulo, 1929. 
ROMAG, Frei Dagoberto. A História dos Franciscanos no Brasil (1500-1659). Curitiba: Imprimatur, 1940

RÖWER, Basílio. O Convento de Santo Antônio do Rio de Janeiro. Petrópolis: Vozes, 1937.

A Ordem Franciscana no Brasil. Petrópolis: Vozes, 1942.

Os Franciscanos no Sul do Brasil. Petrópolis: Vozes, 1944.

. Páginas de História Franciscana no Brasil. Petrópolis: Vozes, 1941.

SANGENIS, Luiz Fernando Conde: Gênese do Pensamento Único em Educação: Franciscanismo e Jesuitismo na História da educação brasileira. Petrópolis, Rio de Janeiro: VOZES, 2006. 197 P; ISBN - 85.326.3252-1.

SANTOS, Ailene Contreiras dos. Estudo Documental da Atuação Jesuítica e Franciscana na Educação do Brasil - Colônia (1500-1808), tese de doutorado: Universidade Federal do Rio de Janeiro, 1974.

TETTEROO, Samuel. A Ordem dos Frades Menores no Brasil: Resumo Histórico Chronologico 1500-1924. São João Del Rei: TYP. Acção Social, 1924.

VAT, Odulfo Van Der. Princípios Da Igreja no Brasil. Petrópolis: Vozes, 1952.

WILLEKE, Venâncio. Escolas Franciscanas do Brasil. In: Revista da Escola de Belas Artes de Pernambuco. Recife, 1961.

. Franciscanos na História do Brasil. Petrópolis: Vozes, 1977.

. Franciscanos no Maranhão e Piauí. Bacabal: Maranhão, 1978.

. Missões e Missionários na Província de Santo Antonio. In. Revista de História. São Paulo, ano XXVIII, n ${ }^{\circ}$ LVI, 1977.

. Missões Franciscanas no Brasil (1500-1975). Petrópolis: Vozes, 1974. 


\section{Notas:}

${ }^{1}$ Mestre em educação pela Universidade Estadual de Maringá - UEM, Doutora em educação pela Universidade Estadual de Campinas - UNICAMP, Pós-doutoranda na Universidade Estadual de Campinas UNICAMP. Membro do Grupo de Pesquisa História, Sociedade e Educação no Brasil - HISTEDBR. taniglesias@yahoo.com.br

${ }^{2}$ Revisão bibliográfica elaborada para a consecução da tese de doutorado intitulada: A experiência Educativa da Ordem Franciscana: Aplicação na América e sua Influência no Brasil Colonial, defendida na Unicamp em fevereiro de 2010 sob a orientação do prof. Dr. Dermeval Saviani, foi considerada por Frei Sandro da Costa, professor de história dos franciscanos no Brasil e atual diretor do Instituto Teológico Franciscano do Brasil, situado em de Petrópolis, a mais completa revisão da categoria elaborada até o momento.

${ }^{3}$ IGLESIAS, Tania Conceição. A Experiência Educativa da Ordem Franciscana: aplicação na América e sua influência no Brasil Colonial. Campinas, 2010. Tese (Doutorado em História e Filosofia da Educação) Universidade Estadual de Campinas (UNICAMP), Fevereiro de 2010.

${ }^{4}$ Os conflitos entre os franciscanos e jesuítas no Brasil são tratados em quase todas as obras históricas sobre as duas ordens, notadamente as que abordam as Missões no Brasil Colonial. Entre elas, quer se destacar as mais importantes: "Novo Orbe Seráfico Brasílico" de Frei Jaboatão (1695-1779) e "História da Companhia de Jesus no Brasil" de Serafim Leite (1880-1969).

${ }^{5}$ Sobre a questão, consultar: Sangenis, 2006.

${ }^{6}$ Sobre as Missões na Paraíba, consultar: Frei Manuel da Ilha. "Narrativa da Custódia de Santo Antonio do Brasil: 1584-1621". Petrópolis: Vozes, 1975; Venâncio Willeke. "Missões Franciscanas no Brasil". Petrópolis: Vozes, 1974 e Antonio de Santa Maria Jaboatão. "Novo Orbe Seráfico Brasílico" ou "Crónica dos Frades Menores da Província do Brasil", Rio de Janeiro: Tipografia Brasiliense de Maximiniano Gomes Ribeiro, 1852-1862.

${ }^{7}$ Sobre as Missões franciscanas no Maranhão, consultar: Venâncio Willeke. Missões Franciscanas no Brasil 1500-1975, Petrópolis, 1974; Franciscanos na História do Brasil, Petrópolis, 1977; Franciscanos no Maranhão e Piauí 1600-1878; 1952-1977, Petrópolis, 1978; Fidelis de Primerio. Capuchinhos em Terra de Santa Cruz, São Paulo, 1942; e Os Missionários Capuchinhos no Brasil, São Paulo, 1929.

${ }^{8}$ Existe uma cópia manuscrita do Regimento das Missões de 1680 no Arquivo da Torre do Tombo, Portugal, que se encontra nos espólios dos franciscanos: OFM, Província de Santo Antonio, Província, maço sete.

7. Foi publicada por Serafim Leite, em História da Companhia de Jesus, tomo IV. Ainda sobre o assunto consultar: Beozzo, José Oscar. Leis e regimentos das Missões. Política indigenista no Brasil. São Paulo: Loyola, 1983.

${ }^{9}$ Cf. Sangenis, 2006.

${ }^{10}$ Frei Samuel Tetteroo (1875-1934) nasceu na Holanda e ingressou na ordem franciscana em 1894. No Brasil, fixou-se em Minas Gerais, onde desempenhou várias atividades, entre elas a de cartógrafo, agrimensor, historiador e escritor. Prestou vários serviços cartográficos a esse Estado pelos quais foi agraciado com medalha de ouro pelo governo de Minas. Foi membro do Instituto Histórico Geográfico de Ouro Preto e escreveu as seguintes obras: "Memória Histórica e Geographica do Município de Jequitinhonha". Teófilo Otoni: Typ. S. Francisco, 1919; e O Município de Theophilo Ottoni. Belo Horizonte: Imprensa oficial de Minas Gerais, 1922. Entretanto, quer-se destacar o livro "A Ordem dos Frades Menores no Brasil”. São João Del Rei: Typ. Ação Social, 1924, que apresenta o resumo histórico-cronológico relativo à Ordem dos Frades Menores de 1500 até 1924.

${ }^{11}$ Data comemorada pelos franciscanos em homenagem ao aparecimento das chagas de Cristo no corpo de São Francisco de Assis em 17 de setembro de 1224. As chagas de Cristo no corpo de São Francisco é tema atualmente abordado por John Sack no livro A Conspiração Franciscana, que trata de desmitificar as feridas aparecidas no corpo do santo como decorrência da lepra, que teria levado Francisco à morte. Esse livro, traduzido e publicado em 2007, no Rio de Janeiro, Sextante, tem sido um dos campeões de venda no mercado literário atual.

${ }^{12}$ Expedições missionárias instituídas pelo cardeal Hugolino de Ostia durante a celebração do Capítulo de Pentecostes na cidade de Assis em 1219, da qual participou São Francisco de Assis, que partiu no mesmo ano em missão para o Egito. 
${ }^{13}$ Bernardo Mott (1885-1968), capuchinho, nasceu em Primerio na Itália e ingressou na ordem franciscana no Brasil no seminário de Taubaté em 1897, tomando o hábito seráfico em 1900, quando mudou seu nome, primeiro para Liberato e posteriormente para Fidelis de Mott Primerio. Professou em 1901 e ordenou-se sacerdote em 1907. Embora tenha exercido o cargo de Custódio Provincial de 1938 a 1942, foi ao magistério que Frei Fidelis dedicou toda a sua vida. Iniciou a carreira de professor no colégio franciscano de Taubaté em 1910, onde também foi reitor do colégio Diocesano. Em São Paulo, foi Superior no Convento Imaculada Conceição e posteriormente diretor do seminário franciscano. Destacou-se como professor de Teologia e Filosofia, além de cultor da Língua portuguesa e História franciscana. Desenvolveu vários trabalhos bibliográficos, entre os quais se quer destacar os de história franciscana, tais como: "Capuchinhos em Terra de Santa Cruz" (1942) e "Os Missionários Capuchinhos no Brasil” (1929).

${ }^{14}$ Designação do conjunto de privilégios concedidos pela Santa Sé aos reis de Portugal e de Espanha. Eles também foram estendidos aos imperadores do Brasil. Tratava-se de um instrumento jurídico tipicamente medieval que possibilitava um domínio direto da Coroa nos negócios religiosos, especialmente nos aspectos administrativos, jurídicos e financeiros. Porém, os aspectos religiosos também eram afetados por tal domínio. Padres, religiosos e bispos eram também funcionários da Coroa portuguesa no Brasil colonial. Isso implica, em grande parte, o fato de que religião e religiosidade eram assuntos de Estado (e vice-versa em muitos casos). No Período Colonial, as atribuições e jurisdições do Padroado eram administradas e supervisionadas por duas instâncias juridicamente estabelecidas no Reino português: a "Mesa de Consciência e Ordens e o Conselho Ultramarino". A primeira, criada pelo rei Dom João III em 1532, julgava, por mandato papal e real, os litígios e as causas de clérigos e de assuntos ligados às "causas de consciência" (práticas religiosas especialmente). A segunda tratava mais dos assuntos ligados à administração civil e ao comércio. Faziam parte de ambas, delegados reais, geralmente doutores em teologia nomeados pela Santa Sé. A união indissociável entre Igreja Católica e os Estados português e espanhol marcou a ação colonizadora desses dois reinos em disputa pela hegemonia no comércio mundial no início dos Tempos Modernos e também as ações pastorais de atrair à fé católica os povos nativos das terras conquistadas e, ainda, a luta contra o avanço do protestantismo. O fim do regime de Padroado no Brasil se deu com a Proclamação da República em 1889.

${ }^{15}$ Campanha pela propagação da fé instituída pela Igreja católica no Século XVII. Foi criada em 1622 pelo Papa Gregório XV e consolidada pelo seu sucessor papa Urbano XIII por meio do "Colégio Urbano de Propaganda" em 1627, que organizou formalmente o processo de difusão da doutrina Cristã nas chamadas "terras de Missões". Sobre a Propaganda Fidei consultar: BIHIMEYER, K. TUECHLE, H. História da Igreja. São Paulo: Paulinas, 1965, v. 1. DALLE, F.R. Igreja e Comunicação Social. São Paulo: Paulinas, 1973.

${ }^{16}$ Henrique Romag (1899-1982) nasceu na Alemanha onde iniciou seus estudos na Ordem Franciscana e adotou o nome de Dagoberto Romag. Veio para o Brasil em 1921 onde continuou o noviciado. Fez votos solenes em 1925 e ordenou-se para o Ministério Sacerdotal em 1926. Especializou-se em História Eclesiástica em Roma em 1930. Exerceu várias funções na Ordem franciscana na Bélgica e no Brasil, mas sua principal atividade foi o magistério, pelo qual recebeu o título honorífico de Lente Geral Jubilado. Frei Romag também se dedicou à história. Publicou vários trabalhos nesse campo, entre eles: "História dos Franciscanos no Brasil desde os Princípios até a criação da Província de Santo Antonio, 1500-1659"; "Compêndio da História da Igreja", 3 volumes; "A Ordem dos Frades Menores"; "Heroínas de Santidade" série de biografias publicadas em "Sponsa Christi”; "Os primeiros Tempos Cristãos", série de artigos publicados em "A Voz de Santo Antonio"; "Os Vigários de Cristo, Intérpretes do Espírito Santo - de São Pedro a Leão III". Artigos publicados em "Espírito Santo"; "Inocêncio XI", publicado na Revista Vozes e "Os Franciscanos e a Imaculada Conceição", publicado na Revista Eclesiástica Brasileira. Dedicou 60 anos à vida religiosa, em sua maior parte no Brasil. Faleceu no Convento de São Francisco em São Paulo, em dezembro de 1982.

${ }^{17} \mathrm{O}$ estabelecimento organizado dos franciscanos no Brasil foi decretado pelo então Ministro Geral da Ordem, Frei Francisco Gonzaga, em 1584, mas teve aprovação pontifícia do Papa Sisto V - Felice Peretti ou Xystus Quintus (1521 -1590) papado (1585-1590) - em 1586. A Custódia de Santo Antonio do Brasil, com sede em Pernambuco, foi dependente da Província com o mesmo nome em Portugal até 1647, quando obteve, por decreto do Ministro Geral da Ordem, Frei João Mazarra de Nápolis, autorização para se tornar independente da Província de Portugal. A Custódia franciscana Brasileira transformou-se em Província em 1675 por meio do breve papal, expedido em 1657 pelo Papa Alexandre VII - Fabio Chigi ou Alexander Septimus (1599-1667), papado (1655-1667). (ROMAG, p. 22-71) 
${ }^{18} \mathrm{O}$ autor refere-se à Missão Franciscana durante a colonização espanhola no sul do Brasil, empreendida pelos Freis Bernardo de Armenta e Alonso Lebrom, de 1538 a 1548 junto aos Índios Carijós.

${ }^{19}$ As Missões a que o autor se refere foram as empreendidas pelos freis capuchinhos franceses e italianos no Brasil colonial.

${ }^{20}$ Frei Odulfo van der Vat (1900-1966) nasceu e estudou na Holanda, ingressou na Ordem Franciscana em 1918. No Brasil, instalou-se em Minas Gerais na Província Franciscana de Santa Cruz, que de 1900 a 1949 era juridicamente dependente da Província dos Santos Mártires Gorcumienses, na Holanda. Doutor em Teologia, foi professor de História Eclesiástica na Faculdade de Teologia da Província Santa Cruz, em Divinópolis-MG, e sócio do Instituto Histórico e Geográfico de Minas Gerais. Suas principais obras são: "Princípios da Igreja no Brasil". Petrópolis: Vozes, 1952, que trata da história eclesiástica do Brasil; e "História Franciscana”. Prov. Franciscana de Santa Cruz. São Paulo: Loyola, 2001. Trata-se da publicação da apostila do autor sobre História da Província Franciscana da Santa Cruz, desde os 3 (três) primeiros frades menores holandeses que para cá vieram em 1899.

${ }^{21}$ Hugo Röwer nasceu na Alemanha em 1877. Ingressou na Ordem Franciscana em seu país natal, porém foi transferido para o Brasil onde iniciou seus estudos na ordem. Chegou ao Recife em 1894, mas, devido à inadaptação ao clima, foi transferido por algum tempo para Blumenau em 1895. Em 1896, começou seu noviciado no Convento de São Francisco na Bahia, onde recebeu o hábito franciscano e o nome de Frei Basílio. Quando terminou o noviciado, cursou filosofia na Bahia e teologia em Petrópolis em 1899, tendo sido ordenado sacerdote em 1901. Faleceu em 1958. Entre as produções históricas de Frei Basílio Röwer, publicadas pela Editora Vozes, Petrópolis, destacam-se: “A Província Franciscana da Imaculada Conceição do Brasil nas festas do Centenário da Independência, de 1922"; "O Convento de Santo Antônio do Rio de Janeiro", de 1937; "Páginas de História Franciscana no Brasil”, de 1941; "A Ordem Franciscana no Brasil”, de 1942; "História da Província Franciscana da Imaculada Conceição do Brasil através de seus provinciais de 1677 a 1901”, de 1951; "Os Franciscanos no Sul do Brasil durante o século XVIII - A Contribuição Franciscana na Formação Religiosa da Capitania das Minas Gerais". "Os Estudos na Província Franciscana da Imaculada Conceição do Brasil nos Séculos XVII e XVIII", de 1954; e "O Convento de N. Senhora da Penha do Espírito Santo", de 1958.

22 Existe um catálogo das composições sacras de Frei Basílio Röwer, conservado pela Editora Vozes, onde constam 63 obras de sua autoria.

23 Vigário cooperador no Convento do Senhor Bom Jesus, em Curitiba, em 1908; superior da pequena residência do Convento São Francisco, em São Paulo de 1909 a 1914; definidor da Província em 1914. Em 1920, tornou-se guardião do Convento de Petrópolis até 1923, quando se tornou guardião do Convento de Santo Antônio no Rio de Janeiro. Em 1934, foi reconfirmado para o mesmo guardianato; de 1938 a 1940, foi superior em Ipanema; em 1941, voltou a residir no Convento de Santo Antônio do Rio, onde exerceu durante 24 anos o cargo de Comissário da Venerável Ordem Terceira de São Francisco da Penitência até a sua morte em 1958.

${ }^{24}$ Frei Jacinto de Palazzolo (? -?) veio da Itália em 1914, trabalhou em Santa Teresa, Conceição do Mato Dentro e no Rio de Janeiro onde foi o primeiro pároco da Igreja São Sebastião na qual coordenara a construção e o acabamento. Designado Custódio, elaborou um programa de ação onde priorizava a Promoção vocacional, a sistematização das Casas de Estudo e o projeto de construção de novo seminário em Nova Friburgo (1951). Escreveu estas obras: Capuchinhos Franceses no Rio de Janeiro. 1612 - 1896. Rio de Janeiro: Edição da Matriz de S. Sebastião dos PP. Capuchinhos, 1952; Nas Selvas dos Vales do Mucuri e de Rio Doce: como surgiu a Cidade de Itambacuri, fundada por Frei Serafim de Gorizia, Missionário Capuchino, 1873-1944 com apresentação de Alceu Amoroso Lima. Petrópolis: Vozes, 1945; Crônica dos capuchinhos do Rio de Janeiro. Guanabara - 1965, ano do IV centenário da fundação da cidade de São Sebastião do Rio de Janeiro. Petrópolis: Vozes, 1966.

${ }^{25}$ Hermann Willeke nasceu em 1906, em Luchtringen na Alemanha onde fez seus primeiros estudos. Entrou para a Ordem Franciscana em 1925, quando recebeu o nome de Frei Venâncio Willeke. Veio para o Brasil em 1926 onde continuou sua formação. Fez noviciado no Convento de Olinda e foi ordenado sacerdote em 1931. Residiu em vários lugares no Brasil e morreu em Recife em 1978.

${ }^{26}$ Frei Venâncio Willeke escreveu sobre várias personalidades da Ordem: Frei Melchior de Santa Catarina, $1^{\circ}$ Custódio Franciscano no Brasil, Vozes, 1961; Frei Antonio de Santa Maria Jaboatão, OFM, 1973; Frei José da SS. Trindade, 1965; Frei Pedro Palácios, RIHGB, 1970; Frei Cristóvam de Lisboa $-1^{\circ}$ Naturalista do Brasil, RIHGB, 1970; Um Grande Brasileiro (Dom Frei Vital), da autoria de Frei Félix de Olívola, 1967; 
destacando o número de escritos sobre frei Vicente do Salvador: Frei Vicente do Salvador - Pai da História do Brasil. Vozes, 1959; Frei Vicente do Salvador - $1^{\circ}$ Missionólogo Brasileiro, A Missiologia de Frei Vicente do Salvador, RIHGS, 1966; Frei Vicente do Salvador, OFM, RIHGB, 1968. Também escreveu sobre outras personalidades: A Abadessa Joana Angélica - Mártir da Independência, Revista Itinerarrium, 1973 ; D. Pedro I e seu Mestre Predileto, Polianteia, 1972; Nóbrega e seus Precursores na Catequese, Polianteia, 1970.

27 Encontramos publicações de Frei Venâncio Willeke em vários periódicos. Consultar: Revista Santo Antonio, anos: 1963, 1954, 1955; Revista do PHAN, 1956, 1968; O Monitor, 1954; Revista da Escola de Belas Artes de Pernambuco, 1961; Revista Vozes, 1972, 1963; Revista de História, 1963, 1964, 1969, 1973, 1974; Revista do Instituto Histórico e Geográfico de Minas Gerais, 1965; Revista campinense de Cultura, 1966; Vida Franciscana, 1973; Revista do Instituto Histórico e Geográfico Brasileiro, 1966, 1967, 1968, 1970, 1972; e referências a publicações internacionais, tais como: Boletim Cultural do Porto, 1965, 1974; Revista Itínerarium, 1974; The Américas, 1956, 1958; Neue Zeitschrift für Missionswissenschaft, 1965, 1968; Franziskanerprovinz Studiem, 1966.

${ }^{28}$ Maria do Carmo Tavares de Miranda nasceu em Vitória de Santo Antão, no dia 6 de agosto de 1926. É bacharelada e licenciada em Letras Clássicas, bacharelada em Filosofia pela UFPE, doutora em Filosofia pela Sorbonne, na França, e doutora e docente-livre em filosofia pela UFPE. Foi diretora-geral do Seminário de Tropicologia da Fundação Joaquim Nabuco, pesquisadora efetiva de centros internacionais de pesquisa e membro titular da Academia Internacional de Filosofia de Arte e da Academia Brasileira de Filosofia. (Academia Pernambucana de Letras). Disponível em: <http://apl.iteci.com.br/default.asp>. Acesso em: 06 mai. 2009.

${ }^{29}$ Entre as obras da autora, destacam-se: Théorie de la Verité chez Edouard Le Roy, de 1957; "Pedagogia do Tempo e da História", de 1965; "Educação no Brasil - Esboço de Estudo Histórico", de 1966; "Os Franciscanos e a Formação do Brasil”, de 1969; "Diálogo e Meditação do Viandante", de 1975; "O Ser da Matéria - Estudo em Kant e Tomás de Aquino", de 1976; "Sobre o Caminho do Campo de Martin Heidegger", de 1977; "Tradução, Introdução e Anotações ao Da Experiência do Pensar de Martin Heidegger", de 1969; e "O Homem e o Tempo", Discurso de Posse da Academia Pernambucana de Letras, de 1983.

${ }^{30}$ Sophia A. Lyra, escritora, teve vários trabalhos publicados. Nasceu no Rio de Janeiro em 1903. Filha do renomado político Augusto Tavares de Lyra sobre quem escreveu a biografia intitulada "O Maior e o Melhor dos Lyras", em 1973. Também produziu outros trabalhos dos quais se destacam: "Assis, Luminosa e Ardente Clareira da Paz", de 1975; "Igreja de Portugal", de 1966; "Madre Joana - a Angélica", de 1968; "Rosas de Neve", de 1974; "Conquistas de Mulher de todos os Tempos", de 1976; "São Francisco de Assis e o Brasil", de 1978, e "Vida Íntima das Moças de Ontem", de 1980.

${ }^{31}$ Por franciscanismo entende-se o estudo que se dedica à compreensão da mística e da espiritualidade da ordem de São Francisco e Santa Clara de Assis. Sobre franciscanismo, consultar: TEIXEIRA, Celso Márcio (org.). Fontes Franciscanas e Clarianas. Petrópolis: Vozes, 2004.

${ }^{32}$ Frei Hugo Fragoso O.F. M fez seus estudos no Brasil e se pós-graduou em Roma, onde defendeu tese sobre as Missões Franciscanas do Grão-Pará. É membro do CEHILA (Comissão de estudos sobre a História da Igreja na América Latina) onde tem publicado vários trabalhos sobre o tema. Foi professor nos Institutos de Teologia do Recife, Ilhéus, Fortaleza e Salvador. Reside atualmente no Convento de são Francisco em Salvador onde tem produzido uma série de trabalhos sobre a restauração da Província de Santo Antonio.

${ }^{33}$ Além de suas publicações pelo CEHILA, entre outros, apostilas nos foram gentilmente cedidas pelo autor, dentre elas: "São Francisco do Paraguaçu: uma história sepultada sob ruínas". Salvador: SCT, 2004.

${ }^{34}$ Não foram encontrados estudos específicos sobre o trabalho educativo desenvolvido pelas franciscanas no Período Colonial. Os trabalhos publicados versam sobre as ordens religiosas femininas no Brasil e abordam o tema sob uma perspectiva ampla.

${ }^{35}$ O CFB - Centro Franciscano do Brasil, sediado em Petrópolis, é o órgão coordenador dos diversos serviços que a Ordem presta a seus membros. Ele é dirigido por um Coordenador responsável pelas atividades nele desenvolvidas e funciona como a casa-mãe que integra todos os franciscanos e franciscanas no Brasil.

36 A FFB-Família Franciscana do Brasil, integrada ao Centro Franciscano, foi criada em 1994 em substituição ao antigo CEFEPAL - Centro de Estudos Franciscanos e Pastorais para a América Latina, que compreende a Experiência de Mística Franciscana. A FFB amplia esses serviços, que passam a abranger, além do caráter religioso, o cultural e mantém, em sua organização, vários departamentos para a consecução de suas atividades cujo objetivo primeiro é a integração dos membros da Ordem Franciscana no Brasil, que 
envolvem desde cursos de formação até a publicação e distribuição de boletins, periódicos e livros que condensam os resultados de suas atividades, estudos e pesquisas.

${ }^{37}$ O DEHIF - Departamento de Estudos de História Franciscana, integrado e mantido pela FFB, é o Serviço que anima, amplia e coordena a historiografia franciscana. Produz, em cooperação com seus membros e pesquisadores em geral, a história da presença franciscana no Brasil, preserva o acervo histórico existente, publica ou reedita trabalhos sobre os franciscanos no Brasil.

${ }^{38}$ Sandro Roberto da Costa (1962-) nasceu em São José dos Campos, São Paulo. Ingressou na Ordem dos Frades Menores no dia 20 de janeiro de 1985. Fez a profissão solene no dia 2 de agosto de 1990 e foi ordenado sacerdote no dia 19 de dezembro de 1992. Fez Mestrado em História da Igreja, na Pontifícia Universidade Gregoriana, em Roma, Itália, de 1994 a1997, e Doutorado em História da Igreja na mesma Universidade, de 1997 a 2000. É vigário paroquial de Nilópolis, RJ, diretor do Instituto Teológico Franciscano (ITF), fundado em 1896 e situado na cidade de Petrópolis, onde se encontra uma das mais importantes bibliotecas teológicas da América Latina. Coordena, junto à FFB, o DEHIF - Departamento de História Franciscana. Entre as suas publicações, destacam-se: "Processo de Decadência da Província Franciscana da Imaculada Conceição do Brasil e Tentativas de Reforma - 1810-1855". Extrato da tese para a obtenção do título de Doutor em História da Igreja. Pontifícia Universidade Gregoriana, Roma, 2000. E "Imaculada, Maria do Povo, Maria de Deus" (org.). Petrópolis: Vozes, 2004.

Recebido em: $\quad$ 19/11/10

Aprovado em: $\quad 21 / 12 / 10$ 